\title{
VOLUNTEER TOURISM AS TOURIST TREND
}

\author{
Sandra Mrvica Mađarac ${ }^{1}$ \\ Mirjana Nedović ${ }^{2}$
}

DOI: https://doi.org/10.31410/LIMEN.2019.25

\begin{abstract}
Modern tourists on their vacations seek for an experiences and activities and one of the possible solutions for active vacation is offered in the form of volunteer tourism. Volunteer tourism is a tourist trend (volunteer plus tourism) that provides humanitarian work and the contribution of tourists to the local community during the holiday season. Through volunteering tourist is directly acquainted with the destination, its culture, problems and local customs and for the tourists through their humanitarian work is provided a sense of value. Volunteer activities can be carried out in the fields of ecology, agriculture, orphanages, animal care, heritage rebuilding, education, etc. In addition to the positive side, the negative side of volunteer tourism has also been criticized. The main argument for this is the attitude that this tourist product implies underdevelopment and poverty as a ,tourist attractions”. For the purpose of this study, a group interview was carried out that includes the students to determine if they were familiar with the concept of voluntarism, whether they would go on this kind of tourist vacation and also what is their opinion on voluntarism.
\end{abstract}

Keywords: Volunteer tourism, Active vacation, Group interview.

\section{INTRODUCTION}

$\mathrm{T}$ oday's tourists, apart from their holidays, during their stay in a tourist destination they seek for the experience and to active spending of their vacations. During their vacation, tourists want to get to know better the local population, their lifestyle and local customs. It is for these reasons that volunteer tourism is one of the possible ways to spend the vacation. As a more decent way of tourist travel, volunteer tourism offers to tourists the opportunity to engage in a humanitarian work in the course of their tourist journey. Volunteer vacations give tourists a sense of purpose while vacationing because the volunteer tourists besides travelling also help people who seek for help. In addition to helping people, there also exists a wide range of humanitarian work that can also be used for tourism purposes. However, volunteer tourism has its criticisms as well. This paper explores attitudes towards volunteerism through a method of group interview and it cites a SWOT analysis intended for the development of volunteer tourism as a form of tourism that can be widely applied.

\section{THE MEANING OF VOLUNTEER TOURISM}

Volunteer tourism is a new trend in tourism offerings that involves an experience that is greater than the travel itself. In addition to containing the tourism component, it also contains its humanitarian character because it includes tourists who wish to spend their holidays actively and participate in humanitarian activities. Volunteer tourism is aimed at the part of the tourist market which wishes to get to know tourist destinations through direct social contact with the local community and to participate in socially responsible programs.

\footnotetext{
$\overline{1}$ College of Applied Sciences 'Lavoslav Ružička”' in Vukovar, Županijska 50, 32000 Vukovar, Croatia

2 College of Applied Sciences 'Lavoslav Ružička”' in Vukovar, Županijska 50, 32000 Vukovar, Croatia
} 
Volunteer tourism is approach to get to know a new country better and to play an important role in that local community. Volunteer tourism can be defined as a combination of volunteer work in a tourist destination with the best traditional elements in that destination, namely: art, culture, history and geography.

Volunteer tourism provides:

- Involving in socially responsible programs implemented in the local community and engaging more deeply with the community in question,

- Mastering the new skills or perfecting the existing skills through work,

- Interactive learning,

- Meeting with the local population, with people you would not meet at a hotel or in another tourist destination,

- Touring and getting to know places that otherwise tourists would never see during the classic tourist tour,

- An opportunity for the new friendships,

- Experience of the true satisfaction after the holiday (Volonturizam, 2019).

Volunteers are tourists who for various reasons are volunteering in an organized manner during their vacation, on the way to help or to alleviate material poverty of certain social groups; they help regenerate the environment or conduct research on various social and environmental issues (Wearing \& McGehee, 2001).

In accordance to the concept of sustainable development of the local community by volunteer tourism are linked all stakeholders of this development, such as: local government, profit and non-profit sector, and from the tourist aspect to incite the possibility of active involvement in local community development, which contributes to the creation of priceless experiences that are remembered through the entire life of an individual (Matošević Radić, Hrabar \& Buzdovačić, 2017).

Before a potential volunteer tourist has engaged with this type of tourist travel, it is necessary to gather information's about organizations that organize volunteer tourists travels that, in addition to the profits made from this type of travel, should take into account the sustainability in volunteering tourism, the needs of the local community and in this way not to jeopardize the market work at a certain location, i.e. because of the presence of volunteer tourism for the local population will not be deprived of the opportunity to work. For this reason, volunteers should educate the local population and create new business opportunities for them.

Usually, the volunteer tourist pays for the costs of his / her own travel and for stay in the destination, and often the costs of organizing a volunteer project in which he or she participates. In contrast to the volunteers who participate in the volunteer projects in their local communities, volunteer tourists work in places that are far from their homes, working in an unfamiliar environment that includes new people, unknown or lesser known cultures, different traditions and different living conditions (Kumaran \& Pappas, 2012). To one's work could be considered as volunteering, it is necessary to be fulfilled three basic parts of volunteer tourism:

- Voluntariness; for their work is an expression of the goodwill of an individual tourist, that is done without any compulsory actions,

- Being unpaid; volunteerism is completely free of charge, with no expected monetary or material compensation, 
- Solidarity; volunteer works out of expression of compassion for others and from a desire to help someone (Travel magazine, 2014).

There are numerous humanitarian activities that can be encompassed by the volunteer tourist travel programs such as: humanitarian assistance, various environmental activities, different ecological actions implied for the development of eco-agriculture, conservation and care of the endangered animal species, restoration of archaeological sites, the fight for human and animal rights, construction of facilities (schools, hospitals, kindergartens, and others), participation at festivals, working on educational projects and so on.

Although it has many advantages, volunteer tourism is often subjected to criticism. This situation may arise when organizations of the volunteer tourist travel have in mind only the wishes and needs of tourists, but not the needs of the community to which the help would be provided (Association „MI“, 2017). It also criticizes the marketing of volunteer tourism programs that promote companies engaged in the organization of volunteer travels, insufficient legal regulation, and screening of potential volunteers before departing for a trip. The moral side of such a trip has also been criticized because underdevelopment and local economic and social problems can be considered as tourist attractions.

Through the development of the tourism product in volunteer tourism it is necessary to distinguish the following factors (Callanan \& Thomas, 2005):

- Length of visit (of the volunteer engagement),

- Level of involvement in the volunteer project (from passive to active inclusion),

- Skills and qualifications of volunteer tourists as participants in relation to a specific project,

- The degree of focus on the volunteer project considering participants' self-realization and contribution to the local community.

In order to create a quality offer of volunteer tourism programs it should be necessary to (Cimerfraj, 2018):

- Set high goals; volunteers are prepared for the difficult tasks if they see a long-term benefit to the local community and if they feel themselves useful,

- Align the skills and knowledge of tourist volunteers with the task; it is necessary to set the conditions that a volunteer tourist must meet in order to participate,

- Condition the length of stay; to harmonize the tourist journey with the duration of the project,

- Ensure that projects are not funded from the volunteer funds.

The cooperation of the for-profit and non-profit sector in the development and implementation of quality volunteer projects creates ,, volunteer tourists partnerships" among all involved stakeholders, such as: volunteers, organizations that organize volunteer trips, travel agencies, online brokers and tour operators who will take over the promotion and distribution of volunteer products, aviation companies that could provide discounts for this type of travel, local non-governmental organizations that implement volunteer programs in the local community, but also the users of the volunteers program (Kumaran \& Pappas, 2012). The business sector has recognized the benefits of collaborating with nonprofits organizations that impact on increasing their productivity, the quality of employment and to maintain positive public image. Non-profit organizations also benefit from this kind of partnership because they include access to special- 
ized skills, build organizational capacity and increase public awareness about the social issues (Association „MI“, 2017). Volunteering tourism has become one of the strongest trends in tourism that meet the needs of well-informed tourists as those who on their personal level show an interest in travel, new and authentic experiences and personal development, with intensive interaction with the local population and striving to bring about positive changes to the region and society they are visiting (Wearing, 2001).

\section{SWOT ANALYSIS OF VOLUNTEER TOURISM DEVELOPMENT}

In Table 1 is shown the SWOT analysis of the development of volunteer tourism, that is, the strengths, weaknesses, opportunities and threats in the environment that affect the development of volunteer tourism. The situational analysis is the basis for setting the right strategy and redefining the goals that wants to be achieved.

Table 1. SWOT analysis of the development of volunteer tourism

\begin{tabular}{|c|c|}
\hline $\begin{array}{l}\text { STRENGHTS } \\
\text { - } \text { the humanitarian character of volunteer tourism } \\
\text { - } \text { a large and unexploited volunteer market } \\
\text { - } \text { a new market segment for tourists } \\
\text { - education of the local population } \\
\text { - increasing the quality of life on the destination } \\
\text { - long-term benefit for the local community } \\
\text { - personal satisfaction of tourists by actively spend- } \\
\text { ing their holidays } \\
\text { - new friendships } \\
\text { - goeting the new cultures and customs }\end{array}$ & $\begin{array}{l}\text { WEAKNESSES } \\
\text { - the commission fee from the humanitarian work } \\
\text { is taken by intermediaries for such travelling } \\
\text { - consideration of poverty and underdevelopment } \\
\text { of tourist attractions } \\
\text { - insufficient legal regulation } \\
\text { - lack of conditions related to the knowledge and } \\
\text { - skills of volunteer tourists } \\
\text { - the length of stay if it's too short } \\
\text { - insufficiently known form of tourism }\end{array}$ \\
\hline $\begin{array}{l}\text { OPPORTUNITIES } \\
\text { - } \text { great opportunities for humanitarian work } \\
\text { - } \text { greater promotion of volunteer tourism } \\
\text { - } \text { joint action of local stakeholders } \\
\text { - } \text { development of new tourism products } \\
\text { - greater promotion of such travels } \\
\text { - } \text { aligning the wishes of volunteer tourists with the } \\
\text { volunteering activities } \\
\text { - } \text { creating volunteer tourists' packages } \\
\text { - } \text { opportunity for further development of civil soci- } \\
\text { - } \text { ability for financing when using the EU funding } \\
\text { - teer tourism travel deals } \\
\text { business opportunity for travel agencies }\end{array}$ & $\begin{array}{l}\text { THREATS } \\
\text { - } \text { replacement for paid work } \\
\text { greater satisfaction of the tourist's needs than the } \\
\text { local community i.e. the volunteer tourism desti- } \\
\text { nation } \\
\text { - financing projects with volunteers' money } \\
\text { - insufficiently aligned skills and knowledge of vol- } \\
\text { unteer tourists with the volunteering tasks }\end{array}$ \\
\hline
\end{tabular}

Source: author's work

From Table 1 is visible that strengths outweigh weaknesses and opportunities outweigh threats, so a possible strategy for the growth and development of volunteer tourism emerges in order for developing strengths and seize advantageous opportunities that appear in the environment. 


\section{RESEARCH METHODOLOGY AND RESULTS}

The data for the survey were collected with the use of the group interview method in October 2019 on a sample of 25 respondents of 20-22 years of age.

An interview method was an oral interview, a special form of conversation that differs from ,ordinary" interview formally, substantively and psychologically; interview was conducted with a specific purpose and objectives to the previously prepared plan, and here we know exactly who the examiner was and who was the respondent (Zelenika, 2011).

The reminder for the group interview consisted of six major questions with regards to the attitudes and preferences toward volunteer tourism. Before the interview has started, the respondents were acquainted with the term volunteer tourism since no one in the group has known what the term volunteer tourism meant.

The results of the study showed that no one in the surveyed group is engaged in volunteering and that no one in the group had ever taken a volunteer travel. If they would be given the opportunity, 13 respondents from the group (52\%) would go on this form of travel and they plan it in the future. They are most interested in caring for the poor and for the animals as well as for preserving the environment as guided activities on a possible volunteer tourist travel. For caring of children and elderly, feeble individuals, agricultural and construction building works no one in the group expressed a desire to participate in a volunteer tourist travel that would involve these activities. If given the opportunity, the segment of the group that was planning a volunteer tourist travel in the future would be happy to go to some of the European countries and to Africa. The group is interested in this form of travel and they consider it as something new and interesting, and at the same time they would present their humanitarian work.

\section{CONCLUSION}

Volunteer tourism combines travel and vacations with humanitarian work in a tourist destination. For the contemporary tourists there is a need for higher goals in their free time, so they seek to leave behind positive results, expand their worldviews and to help people and regions in need of help. Because a lot of unclear rules on volunteers and volunteer tourism when it comes to the process of selection of volunteers, this form of tourism has many critics, therefore, it would certainly need to check volunteers through testing as well as the organizations that provides this form of travel. There are numerous opportunities for volunteer tourism application; from the child care, care for the elderly and feeble, environmental actions, animal care, construction building and others.

The research conducted through a group interview reveals the fact that volunteer tourism is still an unknown and under-recognized form of tourism, but because of its humanitarian character and the discovery of unknown destinations, it has the potential for development. Respondents are most interested in caring for the poor and animals as part of such a travel and so they consider volunteering to be a very interesting form of tourism, and if given the opportunity they would be happy to go to one of the European countries and to Africa. From the group interview analysis, it can be concluded that the respondents have confirmed strategy of growth and development of this form of tourism, hence it could be widely used in many tourist and other destinations. 


\section{REFERENCES}

Association „MI“(2017). Guide for Volunteer trips. Split, Croatia: Association „MI“

Callanan, M., Thomas, S. (2005). Volunteer tourism - Deconstructing volunteer activities within a dynamic environment. In Novelli, M. (Ed.), Niche Tourism - Contemporary issues, trends and cases (pp. 183-200). Oxford: Elsevier, Oxford, UK

Cimerfraj (2018). What is Volunteer tourism. https://www.cimerfraj.hr/ideje/turisticki-trendovi-volonterski-turizam

Kumaran, M., Pappas, J. (2012). Managing Voluntourism. Gainesville, USA: University of Florida

Matošević Radić, M., Hrabar, A., Buzdovačić, F. (2017). The contribution of the voluntourism to the sustainable community development by satisfying the needs of contemporary tourist consumers. The Challenges of today (pp. 165-173). Šibenik, Croatia: Polytechnic of Šibenik

Travel magazine (2014). Humanity in the service of travel. www.travelmagazine.rs

Volonturizam (2019). www.volonturizam.info/hr

Zelenika, R. (2011). Methodology and technology of making scientific and professional work. Rijeka, Croatia: Faculty of Economics and Business Rijeka

Wearing, S. (2001). Volunteer tourism: Experiences that make a difference. Wallingford, UK: CABI.

Wearing, S., McGehee, N.G. (2013). Volunteer tourism. Tourism Management. 38., 120-130. 